\title{
Paint systems formulated with ion-exchange pigments applied on carbon steel. Effect of surface preparation.
}

\author{
N. Granizo, J.M. Vega, I. Díaz, B. Chico, D. de la Fuente and M. Morcillo* \\ Department of Materials Engineering, Degradation and Durability \\ National Centre for Metallurgical Research (CENIM/CSIC) \\ Av. Gregorio del Amo, 8, 28040-Madrid (Spain)
}

\begin{abstract}
Ion exchange pigments are a scientifically very interesting alternative to chromates that have not yet been fully explored. This study considers the following candidate anticorrosive pigments: calcium-exchanged silica ( $\mathrm{Si} / \mathrm{Ca})$, hydrotalcite/vanadate (HT/V) and calcium bentonite (Bentonite/Ca).

Paint systems manufactured with these ion exchange pigments have been subjected to accelerated corrosion laboratory tests: humidity condensation (HC) and salt fog (SF), simulating environments of low and high corrosivity, in order to assess their anticorrosive behavior in comparison with a zinc chromate reference system. For this purpose the degree of coating degradation has been monitored: blistering, underfilm corrosion and delamination from scribe.

Electrochemical impedance spectroscopy (EIS) has allowed us to evaluate and quantify the anticorrosive capacity of these ion exchange pigments when incorporated in the paint coating.

This paper focuses on the effect of several parameters of interest when designing a paint system: a) sanding treatment of the base steel prior to application of the primer paint; $b$ ) pigment concentration in the primer paint coating; and c) application of a topcoat layer over the primer coating.
\end{abstract}

Keywords: ion-exchange pigments, anticorrosive paints, surface preparation, primers, topcoats, mild steel

\footnotetext{
* Corresponding author. Tel: +34915538900; Fax: +34915347425;

E-mail address: morcillo@cenim.csic.es
} 


\section{INTRODUCTION}

In the field of anticorrosive primer paints there is growing interest to find environmentally friendly anticorrosive pigments to replace $\mathrm{Cr}(\mathrm{VI})$ pigments which are highly toxic both to the environment [1] and to human health, with known carcinogenic effects [2]. This has become a major challenge of the last decade for all the sectors involved in metallic protection. One of the alternatives of greatest scientific interest is the use of ion exchange pigments, which are mostly naturally abundant, easily synthesised, releatively cheap, and above all environmentally friendly.

The functioning of these compounds seems to involve a dual protection mechanism [36], which could represent an initial advantage over chromates and most of the other alternatives studied to date, since the inhibiting capacity of the anticorrosive pigment is accompanied by a capacity to retain potentially aggressive ions entering from the exterior. Moreover, the fact that corrosion inhibiting species are only released when the corrosive species pass through the paint coating, and that the amount released depends on the severity of the environment, means that the use of these inhibitors is more "economical" compared to chromates (highly soluble), and therefore long term anticorrosive protection is improved thanks to a lower degree of blistering, which is one of the main paint degradation mechanisms [7-8].

The candidate anticorrosive pigments to provide this type of mechanism belong to the clay family, which is well known for its exchange capacity; hydrotalcites denominated Layer Double Hydroxides (LDHs), also known as anionic clays; and silicon gels exchanged with calcium ions. The common characteristic for the first two families of compounds is the presence of a permanent or intrinsic charge, which is negative for clays and positive for hydrotalcites, as a consequence of isomorphic substitutions which must be balanced with mobile cations and ions for the stability [9-12] and neutrality of

the structure. The high surface area of the silicon/calcium, $60 \mathrm{~m}^{2} \cdot \mathrm{g}^{-1}$, compared to traditional pigments, makes it a solid upon which a great number of surface processes can take place (adsorption/desorption, ion exchange, etc.) [13].

Studies carried out by Granizo [13] using primers formulated with these ion exchange pigments have shown that their adhesion to the base steel is irregular, leading at times to deficient results in anticorrosive terms. For this reason, the present work addresses the need to find suitable conditions for using these pigments, focusing on the effect of surface treatment of the base steel prior to the application of the primer paint, in a simple paint (primer paint), and after the application of a topcoat over the primer (full 
paint system), simulating real applications.

Accordingly, primers incorporating the different anticorrosive pigments ( $\mathrm{Si} / \mathrm{Ca}, \mathrm{HT} / \mathrm{V}$ and Bentonite/Ca as ion exchange pigments) were subjected to various accelerated corrosion laboratory tests at different corrosivities, namely humidity condensation (HC) and salt fog (SF), in comparison with a zinc chromate reference system.

Electrochemical Impedance Spectroscopy (EIS) has been used to assess, quantify and corroborate the anticorrosive capacity of the ion exchange pigments incorporated in the paint coating.

\section{EXPERIMENTAL}

\subsection{Paint systems. Test specimens}

The formulation of all the primer paints used in the present study, with different pigment contents (\% weight) incorporated in the paint coating, is shown in Table 1. A conventional primer pigmented with $10 \%$ zinc chromate was applied as reference (Ref) to compare the effectiveness of the innovative pigments with that of $\mathrm{Cr}(\mathrm{VI})$ compounds. The $\mathrm{Si} / \mathrm{Ca}$ used in this research has been supplied by W.R. GRACE Davison and is type AC5 (maximum particle size no more than $5 \mathrm{~mm}$ ). HT/V and Bentonite/Ca have been carefully synthesised in the laboratory [13] using analytical grade chemical reagents and deionised distilled water to prepare the different solutions for synthesis. The procedures followed for the preparation of $\mathrm{HT} / \mathrm{V}$ and Bentonite/Ca were those proposed by Buchheit [14] and Bohm [15], respectively.

The topcoat when applied on the primer paint was a short linseed oil alkyd/titanium dioxide type paint. The topcoat was only applied on the primers containing what was determined in preliminary exploratory tests to be the most efficient pigment concentration in anticorrosive terms.

To study the effect of surface preparation of the base steel, some series of specimens were prepared without any surface preparation while others were prepared by sanding prior to application of the primer paint. Sanding was performed with abrasive paper ( $\mathrm{SiC}, 600)$. The metallic substrate used in this research was a conventional $3 \mathrm{~mm}$ thickness cold rolled low carbon construction steel sheet.

The different paint formulations were applied on the metallic substrate by aerographic spraying after cleaning the surface with a universal solvent. The reverse sides and edges of the specimens were protected with a thick industrial paint affording very good anticorrosive properties in order to prevent the initiation of corrosion in these areas 
during the tests.

The applied primer thickness was in the $60 \pm 10 \mu \mathrm{m}$ range and the conventional alkyd topcoat enamel thickness applied on the primer was around $100 \pm 10 \mu \mathrm{m}$.

Prior to the start of the test, a scribe was made on the lower part of some specimens, according to standard DIN 53167 [16], in order to assess the coating behaviour and the extent of delamination in areas presenting damage or premature failure.

Coating deterioration during the different tests was determined by visual observation (degree of corrosion, blistering and delamination) and by electrochemical impedance spectroscopy (EIS).

\subsection{Permeability measurement of paint coatings}

Free films of each primer paint (Table 1) were prepared for the different permeability tests.

Water permeability was determined by gravimetric loss, following standard ASTM D1653 [17].

Oxygen and chloride ion permeabilities [18] were determined by the corrosive agent concentration gradient generated on either side of the paint film, determining the oxygen or chloride ion concentration on the face of the film with the lowest concentration, using a previously calibrated oxygen or chloride ion selective electrode. These tests were performed with constant stiring in order to ensure that permeation of the chloride ion or oxygen through the film was due only to the permeability of the free film. This test was performed at a constant temperature of $25 \pm 0.5^{\circ} \mathrm{C}$.

\subsection{Accelerated corrosion tests}

Two accelerated tests with different corrosivities have been performed: a) humidity condensation test (HC), according to standard ISO 6270-1 [19], in a Cleveland type climate cabinet; and b) salt fog test (SF), according to standard ISO 9227 [20].

The specimens tested in the climate cabinets were periodically inspected to assess the degree of blistering (ASTM D 714-56 [21]), corrosion (ASTM D 610-68 [22]), and delamination from the scribe $(\mathrm{mm})$.

\subsection{Electrochemical impedance tests}

The degree of coating deterioration during exposure was also evaluated by means of electrochemical impedance spectroscopy (EIS). 
EIS measurements were performed with an EcoChemie Autolab unit consisting of a PGSTAT30 potentiostat/galvanostat with a FRA2 impedance measurement module. Frequency scans were performed from $100 \mathrm{kHz}$ up to $1 \mathrm{mHz}$, applying a sinusoidal perturbation of $\pm 5 \mathrm{~mW}$ at the system's corrosion potential, acquiring five points per decade. A $0.1 \mathrm{M} \mathrm{Na}_{2} \mathrm{SO}_{4}$ solution was generally used as electrolyte. The behaviour of the paint coating was also evaluated in a $0.1 \mathrm{M} \mathrm{NaCl}$ solution.

The impedance data obtained was analysed using ZView® impedance software (Version 2.9c, Scribner Associates, Inc., USA). The tested area was $9.62 \mathrm{~cm}^{2}$ for a volume of 15 $\mathrm{ml}$. The electrochemical system was completed with a stainless steel counter electrode and a $\mathrm{Ag} / \mathrm{AgCl}$ reference electrode.

\section{RESULTS}

\subsection{Adhesion test}

Adhesion tests were performed following standard ISO 2406:1991 [23].

Figure 1 displays the adhesion results for primer paints formulated with ion exchange pigments applied on steel. Attention is drawn to the notable lack of adhesion of the primers formulated with $\mathrm{Si} / \mathrm{Ca}$ and the good adhesion of those formulated with HT/V. The primers pigmented with Bentonite/Ca show intermediate specific adhesion, similar to that of the zinc chromate reference primer.

\subsection{Permeability measurements}

Figure 2 displays the water, oxygen and chloride ion permeability values obtained for the tested primer paints.

\subsection{Accelerated corrosion tests}

The most relevant results found in relation with each test: rusting, blistering and delamination at the scribe, will be presented during the discussion.

\subsection{Electrochemical impedance measurements}

The most relevant results found in relation with this test will be presented during the discussion.

Tables 2 and 3 show the coating resistance values $\left(\mathrm{Rp}, \Omega \cdot \mathrm{cm}^{-2}\right)$, calculated from the impedance diagrams, for paint coatings applied on steel with and without preliminary sanding treatment, after 400 hours of exposure to $\mathrm{HC}$ and SF. 


\section{DISCUSSION}

\subsection{Silicon/Calcium (Si/Ca)}

The permeability of the primers with 5 and $10 \% \mathrm{Si} / \mathrm{Ca}$ is very similar, and in general the $15 \%$ composition is the most permeable (Figure 2). It is not surprising that the permeability of paint films in the different aggressive environments increases in line with the pigment content in the coating. With a low pigment concentration, a continous polymeric lattice is obtained and the pigment particles are randomly distributed in a polymer matrix. As the pigment concentration rises, the amount of resin (binder) may be insufficient to agglutinate all the particles, leading to gaps in the paint coating structure which favour the transfer of aggressive agents to the base metal.

In consonance with this behaviour, primer films with $15 \% \mathrm{Si} / \mathrm{Ca}$ show the lowest pore resistance $(\mathrm{Rp})$ of the three compositions in immersion tests in $0.1 \mathrm{M} \mathrm{NaCl}$, as can be seen in Figure 3, left. In contrast, the $10 \%$ primer presents the highest resistance, showing a practically capacitive behaviour in the impedance diagrams (Figure 3, right), similar to that of the zinc chromate primer.

The optimum pigment concentration, with which the most suitable anticorrosive properties are obtained, seems to be close to $10 \%$ for this pigment. However, these characteristics of the paint films pigmented with $\mathrm{Si} / \mathrm{Ca}$ need to be compared with the behaviour observed in the two accelerated laboratory tests, humidity condensation (HC) and salt fog (SF), which simulate atmospheres of low and high corrosivity, respectively. In high humidity atmospheres, like that simulated in the humidity condensation test, processes involving the entry of water through the coating are favoured, giving rise to solubility of the pigment and possible ion exchange processes [24] in the path through the bulk coating towards the metal/paint interface. This creates appropriate conditions for osmotic blistering (closely related to pigment solubility) and underfilm corrosion processes, depending on the inhibiting characteristics of the solubilised pigment.

The humidity condensation test shows that $\mathrm{Si} / \mathrm{Ca}$ primers experience considerable deterioration due to osmotic blistering, as does the zinc chromate (see Figure 4, left), confirming the high solubility of both pigments.

An increase in thickness, for instance by applying a topcoat, should reduce the degree of blistering by lowering the water molecule permeation rate through the paint coating, improving the barrier effect. This has been confirmed and the results are shown in Figure 4, right, where a slight decrease can be seen in the degree of blistering with the complete system. 
Nevertheless, this behaviour is not at odds with good anticorrosive properties, in which, as already noted, the corrosion inhibiting properties of the pigment come into play. Note the excellent behaviour of all the primers in terms of the degree of corrosion in this test. The primer with $10 \% \mathrm{Si} / \mathrm{Ca}$ has shown excellent electrochemical behaviour at the start of the test, with a similar Rp to the zinc chromate after 68 hours of exposure (Figure 5, left), thus confirming the acceptable inhibiting properties of both pigments. As to which of the two pigments affords the best inhibiting properties, the results for rusting at the scribe displayed in Figure 5 (right) leave no doubt about the preponderance of the zinc chromate.

It should nevertheless be mentioned that the coating formulated with $\mathrm{Si} / \mathrm{Ca}$ delaminates from the scribe, confirming the previously noted low adhesion of the primer with $10 \%$ $\mathrm{Si} / \mathrm{Ca}$ (Figure 1). This deficient behaviour in terms of lack of adhesion of this coating on a smooth (unprepared) steel surface, which facilitates its delamination at the scribe when exposed to an aggressive atmosphere (Figure 6), may be improved by a surface treatment like sanding, which promotes greater specific adhesion of the paint film to the base metal.

Sanding of the steel upon which the coatings are applied leads to an improvement in the extent of delamination from the scribe for both the primer and the complete system (primer + topcoat), see Figure 6.

This better behaviour of the specimens with sanding treatment of the steel surface is confirmed in the electrochemical study performed during the course of the test, which reveals higher coating resistance values than those of coatings applied on specimens without sanding. The effect of surface treatment of the steel is especially notable in the behaviour of the primers (Tables 2 and 3).

The salt fog test, which is of greater corrosivity due to the presence of chloride ions, leads to more considerable deterioration of the primers.

The reference zinc chromate primer presents good behaviour during salt fog exposure, as has repeatedly been shown for this pigment in saline environments. In contrast, the $\mathrm{Si} / \mathrm{Ca}$ primer presents great deterioration in terms of blistering, as in the humidity condensation test, along with considerable delamination and underfilm corrosion (Figure 7).

As in the case of humidity condensation, the application of a surface sanding treatment improves the adhesion of the metal/paint system, promoting a notable decrease in blistering for the primer, and to a lesser extent for the complete system, as well as less 
underfilm corrosion, close to that shown by the zinc chromate primer. Nevertheless, despite the preparation of the metallic surface the amount of deterioration is quite considerable, as is delamination from the scribe, mainly with the primer (Figure 8). This improvement in the anticorrosive behaviour of the specimens formulated with $\mathrm{Si} / \mathrm{Ca}$ and surface treatment of the steel has also been corroborated by the higher Rp values found (Tables 2 and 3).

The effect of surface treatment of the steel during accelerated exposure is especially notable in the behaviour of the primers (Figure 9, left), where the impedance plot changes with surface preparation from a closed and defined arc at high frequencies to a capacitive and open arc. The effect of sanding does not produce a relevant change on the complete paint system (Figure 9, right).

\subsection{Hydrotalcite/Vanadate (HT/V)}

Primer paint films formulated with HT/V exhibit excellent specific adhesion on steel surfaces, surpassing the other evaluated formulations, as can be seen in the results shown in Figure 1.

Another parameter evaluated for the unaged primers, was the evolution of pore resistance ( $\mathrm{Rp}$ ) in $0.1 \mathrm{M} \mathrm{NaCl}$ (Figure 10). The primer pigmented with HT/V 5\% shows the closest resistances to zinc chromate.

In the humidity condensation test, the degree of blistering on the primer paint with HT/V, while considerable, was less than with the rest of the coatings (Figure 11, left). Furthermore, the extent of delamination from the scribe was also very small, confirming the excellent adherent properties of these formulations on steel (Figure 11, right). With regard to underfilm corrosion, this starts before deterioration, in contrast to the reference system and $\mathrm{Si} / \mathrm{Ca}$, although the amount of deterioration was very close to that of the reference zinc chromate primer at the end of exposure (grade 9). Electrochemical impedance results (Figure 12) indicate considerable deterioration of the primer with $\mathrm{HT} / \mathrm{V}$, which is noted from the initial stages of testing, with very low pore resistance values throughout the test, of the order of $10^{3} \Omega . \mathrm{cm}^{-2}$, as can be seen in Table 2 .

Sanding treatment of the steel surface has yielded only a very slight improvement in the protective effect (Figure 13). This can be seen in relation with deterioration due to blistering. From the electrochemical point of view, this has also been corroborated by a slightly higher Rp of the primer applied on steel with surface sanding treatment (see Table 2). It should be borne in mind again that the primer films pigmented with HT/V 
already present good adhesion to the base steel.

Of all the evaluated compositions, the 5\% pigment content was considered the most appropriate for the application of a topcoat.

The complete system with HT/V has shown an excellent state of protection. As can be seen in Figure 14, right, the Rp values are higher than the complete zinc chromate system after 200 hours of exposure and higher than the other coatings formulated with $\mathrm{Si} / \mathrm{Ca}$ and Bentonite/Ca throughout the course of the test.

The complete paint system presented a very small extent of delamination from the scribe, compared to the other systems, but rusting was far greater than with the zinc chromate formulation, again indicating the supremacy of the latter pigment in terms of inhibitive properties.

The application of a topcoat on the primer paint applied on sanded steel surfaces did not lead to better blistering behaviour of the paint system (Figure 15).

In the salt fog test, deterioration due to blistering and underfilm corrosion is more intense on the primer with HT/V than on the zinc chromate primer, although the degree of blistering is lower than with the rest of the ion exchange pigment formulations. The electrochemical study corroborates the good behaviour of the zinc chromate primer compared to the others. This formulation presents high $\mathrm{Rp}$ values throughout the exposure time and capacitive behaviour, as can be seen in Figure 16 left, after 400 hours of exposure. In contrast, the Nyquist plot for the primer formulated with HT/V is typical of paints that afford little protection right from the start of the test (Figure 16, right), and an active metal/paint interface has developed over time. The Rp values obtained during the test were low, as can be seen in Table 2 .

Sanding treatment of the steel surface has apparently produced a very slight improvement in the protective effect of the primer paint and the complete system, showing small, barely perceptible decreases in the degree of corrosion and blistering. From the electrochemical point of view, this has been corroborated by a slightly higher magnitude of Rp for the primer applied on steel with surface sanding treatment (see Table 2) and similar values for the complete system (see Table 3), already in an advanced state of deterioration, also corroborating the good adhesion of these primers to the base steel.

The application of a conventional synthetic enamel topcoat layer over the primer paint leads to greater protection and less deterioration in the salt fog test (less blistering and rusting, as was to be expected, due to the barrier effect). From the electrochemical point 
of view, the complete system with HT/V showed good behaviour compared to the primer alone, with high Rp values (see Table 3).

\subsection{Bentonite/Ca (Bentonite/Ca)}

With regard to the results obtained on paint films formulated with Bentonite/Ca, the metal/paint specific adhesion of the primer paint is intermediate between the $\mathrm{Si} / \mathrm{Ca}$ and HT/V paints and similar to that of the zinc chromate primer (Figure 1).

The permeability of free films pigmented with Bentonite/Ca shows high water vapour permeation rates and relatively low oxygen and chloride ion permeabilities (Figure 2).

In consonance with the above, the evolution of coating resistance with immersion time in $0.1 \mathrm{M} \mathrm{NaCl}$ shows the poor behaviour of the primer paints with Bentonite/Ca, which is well below that of the zinc chromate primer (Figure 17).

In the condensing humidity test, blistering of the primer paint with Bentonite/Ca was observed from the start of the test (24 hours) (Figure 18, left) as a consequence of the high water absorption capacity of bentonites. With regard to corrosion, this primer paint presents the worst results of all the tested primers (Figure 18, left). Moreover, the extent of delamination is considerable (Figure 18, right), the greatest recorded in all the accelerated tests.

The electrochemical resistance study reveals intense deterioration of the Bentonite/Ca formulation, with low Rp values (Table 2) and the typical Nyquist plot of systems providing little protection, with defined, small diameter high frequency arcs (see Figure 19) after 200 hours of exposure.

Of the three tested primers, the $5 \%$ Bentonite/Ca formulation is that which affords the "better" protection during exposure, as can be seen in Figure 19.

Sanding treatment of the steel surface of the specimens painted with the Bentonite/Ca primer for exposure in the humidity condensation cabinet has led to less deterioration due to blistering and underfilm corrosion (Figure 20) at the start of exposure, although greater deterioration is appreciated over the length of the exposure time, as corroborated in the electrochemical study. Thus, after 400 hours of exposure the Nyquist plot for the primer is typical of a highly deteriorated system, showing lower Rp values than those shown by the primer applied on the metal without surface treatment (Table 2).

The application of a synthetic enamel topcoat layer provides greater protection by its barrier effect, reducing deterioration due to underfilm corrosion and blistering (slight improvements), although the latter continues to be important and is observed from the 
start of accelerated exposure (Figure 21).

This improvement in the protection of the base steel by the complete Bentonite/Ca system, while not equalling the behaviour of the complete zinc chromate system, is reflected in the electrochemical impedance measurements by higher Rp values than those shown by the primer alone (Table 2).

In the salt fog test the Bentonite/Ca primer has shown an acceptable degree of corrosion (grade 8) without equalling the protection afforded by the zinc chromate primer (grade 9). Nevertheless, blistering is severe, below 4, even from the first hours of exposure. Delamination from the scribe has not reached any great extent and has been very similar to that of the zinc chromate primer. Electrochemically, the primers present considerable deterioration, with very low Rp values throughout the exposure time (Table 2).

Of the three formulations, the primer with the highest Rp values, and thus offering the best protection, has been the 5\% Bentonite/Ca primer, which also presents the least delamination from the scribe.

\section{CONCLUSIONS}

- Good adhesion of the metal/paint system is important to delay underfilm corrosion and coating delamination in damaged areas. The best specific adhesion of all the different anticorrosive coatings is shown by the formulations with HT/V. It has also been seen that preliminary sanding treatment of the base steel prior to application of the primer paint considerably improves the adhesion of coatings pigmented with $\mathrm{Si} / \mathrm{Ca}$ and Bentonite/Ca.

- The application of a topcoat layer over the primer paint reinforces the barrier effect of the paint system. The full (primer + topcoat) paint systems in which the primer has been formulated with ion exchange pigments may represent an environmentally friendly alternative compared with pigments based on hexavalent chromium compounds. This is the case in moderate environments, such as condensing humidity, (e.g. with HT/V), and even in more corrosive environments, such as salt fog (e.g. with $\mathrm{Si} / \mathrm{Ca})$.

- The Bentonite/Ca paint systems have generally shown very poor behaviour, well below that of the zinc chromate reference system.

\section{ACKNOWLEDGEMENTS}

This work has been carried out with the financial assistance of the Spanish Ministry of 
Education and Science to project MAT-2005-06261. The authors are grateful to Grace

Davison and Süd-Chemie España, S.L and to Tolsa S.A. for supplying the $\mathrm{Si} / \mathrm{Ca}$ and Bentonite/Ca pigments, respectively, and to Productos Diez, and especially Jesús Guzmán, for manufacturing the primer and topcoat paints used in this work.

\section{REFERENCES}

[1] S.A. Katz, H. Salem, J. Appl. Toxicol. 13 (1993) 217.

[2] S. Langard, T. Norseth, Br. J. Ind. Med. 32 (1975) 62.

[3] B.P.F. Goldie, Prot. Coat. Eur. 6 (2001) 2.

[4] I.M. Zin, L.M. Bilyi, I.P. Gnyp, M .B. Ratushna, Mater. Sci. 40 (2005) 605.

[5] F. Deflorian, S. FelhosiI, L. Rossi, P. Fedrizzi, L. Bonora, Macromol. Symp 187 (2002) 87.

[6] L.W. Vasconcelos, I.C.P. Margarit, O.R. Mattos, F. L. Fragata, A. S. B. Sombra, Corros. Sci. 43 (2001) 2291.

[7] J. Sinko, Prog. Org. Coat. 42 (2001) 267.

[8] A. Kalendová, J. Snupárek, P. Kalenda, Dyes Pigm. 30 (1996) 129.

[9] R.E. Grim, Clay Mineralogy, McGraw Hills, New York, 1968.

[10] S. J. Palmer, A. Soisonard, R. L. Frost, J. Colloid Interface Sci. 329 (2009) 404.

[11] S. J. Palmer, R. L. Frost, T. Nguyen, Coord. Chem. Rev. 253 (2009) 250.

[12] S. Miyata, Clays Clay Miner. 31 (1983) 305.

[13] N Granizo. Ph. Doctoral Thesis, Universidad de Alcalá (Spain) 2010.

[14] R.G. Buchheit, H. Guan, S. Mahajanam, F. Wong, Prog. Org. Coat 47 (2003) 174.

[15] S. Bohm, H.N. McMurray, D. A. Worsley, S.M. Powell, Mater. Corros. 52 (2001) 896.

[16] DIN 53167. Testing of paints, Varnishes and Similar Coating Materials; Salt Spray Test Coating and Similar Coating (1983).

[17] ASTM D 1653. Standard Test Methods for Water Vapor Transmission of Organic Coating Films (1999).

[18] W. Funke et al., Proc. XV Fatipec Congr., Amsterdam 1980.

[19] ISO 6270. Paints and varnishes -- Determination of Resistance to Humidity -Part 1: Continuous Condensation (1998).

[20] ISO 9227. Corrosion Tests In Artificial Atmospheres -- Salt Spray Tests (2006).

[21] ASTM D-714. Evaluating Degree of Blistering of Paints (1987). 
[22] ASTM D610-08. Standard Practice for Evaluating Degree of Rusting on Painted Steel Surfaces (1998).

[23] ISO 2409:1991. Paints and Varnishes-Cross cut test. ISO, Geneve, Switzerland (1992).

[24] N. Granizo. Pending publication. 
Table 1. Formulation of the primer paints used, showing composition as $\%$ wt of components

\begin{tabular}{|c|c|c|}
\hline Vehicle & Anticorrosive pigment & Charges \\
\hline \multirow{12}{*}{$\begin{array}{l}\text { Linseed-soybean oil modified } \\
\text { alkyd resin }(35.5)\end{array}$} & $\mathrm{ZnCrO}_{4}(10)$ & $\begin{array}{c}\mathrm{TiO}_{2}(20) \\
\mathrm{CaCO}_{3}(15)\end{array}$ \\
\hline & $\mathrm{Si} / \mathrm{Ca}(5)$ & $\begin{array}{r}\mathrm{TiO}_{2}(20) \\
\mathrm{CaCO}_{3}(20)\end{array}$ \\
\hline & $\mathrm{Si} / \mathrm{Ca}(10)$ & $\begin{array}{c}\mathrm{TiO}_{2}(20) \\
\mathrm{CaCO}_{3}(15)\end{array}$ \\
\hline & $\mathrm{Si} / \mathrm{Ca}(15)$ & $\begin{array}{c}\mathrm{TiO}_{2}(20) \\
\mathrm{CaCO}_{3}(10)\end{array}$ \\
\hline & $\mathrm{HT} / \mathrm{V}(5)$ & $\begin{array}{c}\mathrm{TiO}_{2}(20) \\
\mathrm{CaCO}_{3}(20)\end{array}$ \\
\hline & $\mathrm{HT} / \mathrm{V}(10)$ & $\begin{array}{c}\mathrm{TiO}_{2}(20) \\
\mathrm{CaCO}_{3}(15)\end{array}$ \\
\hline & $\mathrm{HT} / \mathrm{V}(15)$ & $\begin{array}{c}\mathrm{TiO}_{2}(20) \\
\mathrm{CaCO}_{3}(10)\end{array}$ \\
\hline & Bentonite/Ca (5) & $\begin{array}{c}\mathrm{TiO}_{2}(20) \\
\mathrm{CaCO}_{3}(20)\end{array}$ \\
\hline & Bentonite/Ca (10) & $\begin{array}{c}\mathrm{TiO}_{2}(20) \\
\mathrm{CaCO}_{3}(15)\end{array}$ \\
\hline & Bentonite/Ca (15) & $\begin{array}{c}\mathrm{TiO}_{2}(20) \\
\mathrm{CaCO}_{3}(10) \\
\end{array}$ \\
\hline & \multicolumn{2}{|c|}{ Xilene (disolvent) (17.2) } \\
\hline & \multicolumn{2}{|c|}{ Others $(2.3)$} \\
\hline
\end{tabular}


Table 2. Coating resistance values $\left(\mathrm{Rp}, \Omega . \mathrm{cm}^{-2}\right)$ of the primer paints applied on steel with and without a preliminary abrasive sanding treatment, after 400 $\mathrm{h}$ of exposure to $\mathrm{HC}$ and SF respectively

\begin{tabular}{c|cc|cc}
\hline & \multicolumn{2}{|c|}{ Condensing Humidity } & \multicolumn{2}{c}{ Salt spray } \\
\cline { 2 - 5 } & No SANDING & SANDING & No SANDING & SANDING \\
\hline Zinc Chromate (10\%) & $9.76 \times 10^{4}$ & $5.29 \times 10^{4}$ & $4.41 \times 10^{6}$ & $6.18 \times 10^{8}$ \\
$\mathrm{Si} / \mathrm{Ca}(5 \%)$ & $3.39 \times 10^{3}$ & $5.97 \times 10^{5}$ & $1.29 \times 10^{2}$ & $2.55 \times 10^{5}$ \\
$\mathrm{Si} / \mathrm{Ca}(10 \%)$ & $3.92 \times 10^{2}$ & $4.23 \times 10^{4}$ & $2.03 \times 10^{3}$ & $1.04 \times 10^{6}$ \\
$\mathrm{Si} / \mathrm{Ca}(15 \%)$ & $4.86 \times 10^{3}$ & $6.89 \times 10^{3}$ & $1.99 \times 10^{2}$ & $3.98 \times 10^{4}$ \\
$\mathrm{HT} / \mathrm{V}(5 \%)$ & $2.68 \times 10^{3}$ & $6.75 \times 10^{3}$ & $1.27 \times 10^{2}$ & $1.15 \times 10^{4}$ \\
$\mathrm{HT} / \mathrm{V}(10 \%)$ & $4.38 \times 10^{3}$ & $9.25 \times 10^{3}$ & $2.38 \times 10^{3}$ & $1.43 \times 10^{6}$ \\
$\mathrm{HT} / \mathrm{V}(15 \%)$ & $2.71 \times 10^{3}$ & $2.60 \times 10^{3}$ & $4.89 \times 10^{2}$ & ------ \\
Bentonite/Ca (5\%) & $2.18 \times 10^{3}$ & $2.48 \times 10^{2}$ & $2.83 \times 10^{1}$ & $6.12 \times 10^{1}$ \\
Bentonite/Ca (10\%) & $2.81 \times 10^{3}$ & $2.83 \times 10^{3}$ & $1.85 \times 10^{1}$ & ------- \\
Bentonite/Ca (15\%) & $8.13 \times 10^{1}$ & $5.18 \times 10^{3}$ & $1.27 \times 10^{1}$ & ------- \\
\hline
\end{tabular}


Table 3. Coating resistance values $\left(\mathrm{Rp}, \Omega \cdot \mathrm{cm}^{-2}\right)$ of the full (primer + topcoat) paint systems applied on steel with and without a preliminary abrasive sanding treatment, after $800 \mathrm{~h}$ and $575 \mathrm{~h}$ of exposure to $\mathrm{HC}$ and SF respectively.

\begin{tabular}{c|cc|cc}
\hline & \multicolumn{2}{|c|}{ Condensing Humidity $(800 \mathrm{~h})$} & \multicolumn{2}{c}{ Salt spray $(\mathbf{5 7 5} \boldsymbol{h})$} \\
\cline { 2 - 5 } & No SANDING & SANDING & No SANDING & SANDING \\
\hline Zinc Chromate (10\%) & $1.17 \times 10^{7}$ & $4.6 \times 10^{5}$ & $4.59 \times 10^{7}$ & $1.80 \times 10^{9}$ \\
$\mathrm{Si} / \mathrm{Ca}(10 \%)$ & $2.27 \times 10^{3}$ & $2.40 \times 10^{3}$ & $5.19 \times 10^{8}$ & $6.61 \times 10^{9}$ \\
$\mathrm{HT} / \mathrm{V}(5 \%)$ & $3.90 \times 10^{4}$ & $2.62 \times 10^{4}$ & $1.26 \times 10^{7}$ & $1.28 \times 10^{7}$ \\
Bentonite/Ca (5\%) & $8.10 \times 10^{3}$ & $5.87 \times 10^{5}$ & $8.04 \times 10^{8}$ & $2.48 \times 10^{9}$ \\
\hline
\end{tabular}




\section{FIGURE CAPTIONS}

Figure 1. Adhesion results for paint coatings (primers) formulated with ion exchange pigments and applied on steel, according to standard ISO 2409:1991 (E). "0" = excellent adhesion, and "5" = complete lack of adhesion.

Figure 2. Water vapor, oxygen and chloride ion permeabilities of free paint films formulated with ion-exchange pigments (NT- No tested. Films fractured)

Figure 3. Left: Evolution with time of exposure in $\mathrm{NaCl} 0.1 \mathrm{M}$ of coating resistance $(\mathrm{Rp})$ for the primers pigmented with $\mathrm{Si} / \mathrm{Ca}$ and $\mathrm{ZnCrO}_{4}$ (Ref). Right: Impedance Nyquist diagrams after 21 days of exposure.

Figure 4. Evolution with time of exposure in $\mathrm{HC}$ of rusting and blistering grades for primers (left) and full paint systems (right) pigmented with $\mathrm{Si} / \mathrm{Ca}$ and $\mathrm{ZnCrO}_{4}$ (Ref).

Figure 5. Evolution with time of exposure in $\mathrm{HC}$ of coating resistance (Rp) (left) and oxidation at the scribe (right) for primers pigmented with $\mathrm{Si} / \mathrm{Ca}$ and $\mathrm{ZnCrO}_{4}(\mathrm{Ref})$.

Figure 6. Evolution with time of exposure to $\mathrm{HC}$ of delamination at the scribe for primers (left) pigmented with $\mathrm{Si} / \mathrm{Ca}$ and $\mathrm{ZnCrO}_{4}$ (Ref) and full paint systems (right) with (discontinuous line) and without (continuous line) a sanding surface treatment.

Figure 7. Evolution with time of exposure to SF of rusting and blistering (left) and delamination at the scribe (right) for primers pigmented with $\mathrm{Si} / \mathrm{Ca}$ and $\mathrm{ZnCrO}_{4}(\mathrm{Ref})$

Figure 8. Evolution with time of exposure to SF of rusting and blistering (left) and delamination at the scribe (right) for primers pigmented with $\mathrm{Si} / \mathrm{Ca}$ and $\mathrm{ZnCrO}_{4}(\mathrm{Ref})$ applied over sanded steel.

Figure 9. Impedance Nyquist diagrams (left) and delamination at the scribe (right) for primers (left) and full paint systems (right) pigmented with $\mathrm{Si} / \mathrm{Ca}$ and $\mathrm{ZnCrO}_{4}$ (Ref) exposed to SF. Effect of sanding (discontinuous line) treatment.

Figure 10. Evolution with time of exposure in $\mathrm{NaCl} 0.1 \mathrm{M}$ of coating resistance (Rp) for primers pigmented with $\mathrm{HT} / \mathrm{V}$ and $\mathrm{ZnCrO}_{4}$ (Ref).

Figure 11. Evolution with time of exposure in $\mathrm{HC}$ of rusting and blistering (left) and delamination at the scribe (right) for primers pigmented with HT/V and 
$\mathrm{ZnCrO}_{4}$ (Ref).

Figure 12. Impedance Nyquist diagrams for primers pigmented with HT/V (5 and $10 \%)$ and $\mathrm{ZnCrO}_{4}$ (Ref) exposed to $\mathrm{HC}$, after $115 \mathrm{~h}$ of exposure.

Figure 13. Evolution with time of exposure to $\mathrm{HC}$ of blistering for primers pigmented with $\mathrm{HT} / \mathrm{V}$ and $\mathrm{ZnCrO}_{4}$ (Ref). Effect of sanding treatment (discontinuous line) of steel.

Figure 14. Evolution with time of exposure to $\mathrm{HC}$ of coating resistance for full paint systems pigmented with $\mathrm{HT} / \mathrm{V}(5 \%)$ and $\mathrm{ZnCrO}_{4}$ (Ref), without (left) and with (right) a sanding treatment of steel.

Figure 15. Evolution with time of exposure to $\mathrm{HC}$ of rusting and blistering for full paint systems pigmented with $\mathrm{HT} / \mathrm{V}(5 \%)$ and $\mathrm{ZnCrO}_{4}$ (Ref), without (left) and with (right) a sanding treatment of steel.

Figure 16. Impedance Nyquist diagrams for primers pigmented with HT/V (5\%) and $\mathrm{ZnCrO}_{4}$ (Ref) exposed to salt fog.

Figure 17. Evolution with time of exposure to $\mathrm{NaCl} 0.1 \mathrm{M}$ of coating resistance (Rp) for primers pigmented with Bentonite/Ca and $\mathrm{ZnCrO}_{4}$ (Ref).

Figure 18. Evolution with time of exposure to $\mathrm{HC}$ of rusting and blistering for primers pigmented with Bentonite/Ca and $\mathrm{ZnCrO}_{4}$ (Ref).

Figure 19. Impedance Nyquist diagrams for primers pigmented with Bentonite /Ca after $200 \mathrm{~h}$ of exposure to $\mathrm{HC}$.

Figure 20. Evolution with time of exposure to $\mathrm{HC}$ of rusting and blistering for primers pigmented with Bentonite/Ca and $\mathrm{ZnCrO}_{4}(\mathrm{Ref})$ applied over sanded steel.

Figure 21. Evolution with time of exposure to $\mathrm{HC}$ of blistering for primers (discontinuous line) and full paint systems (continuous line) pigmented with Bentonite/Ca (5\%) and $\mathrm{ZnCrO}_{4}(\mathrm{Ref})$. 

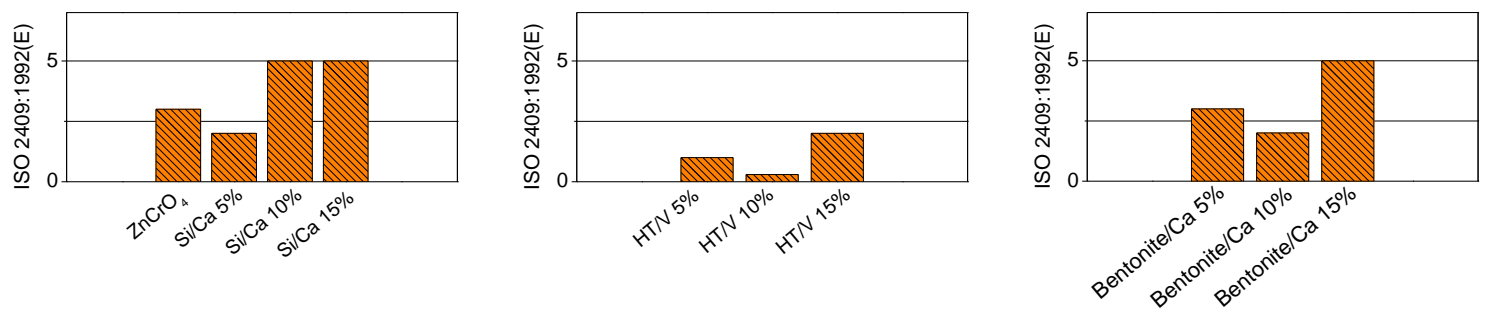

Figure 1 
$\mathrm{H}_{2} \mathrm{O}$
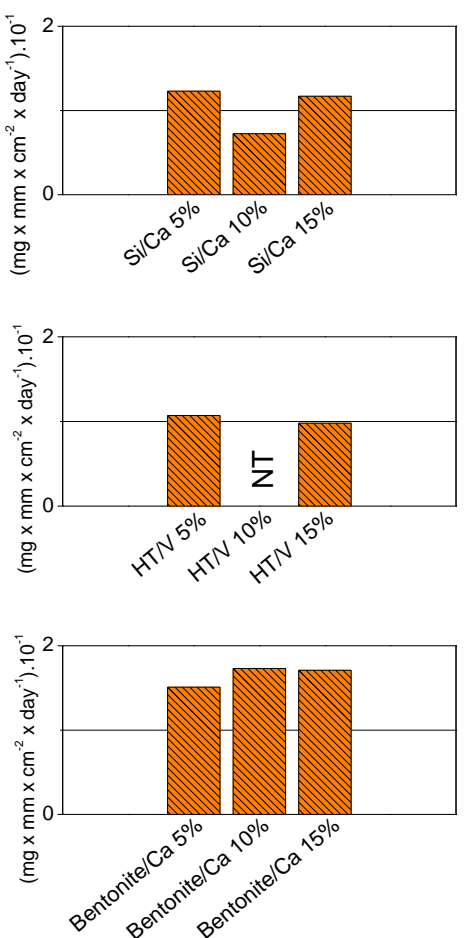

$\mathrm{O}_{2}$
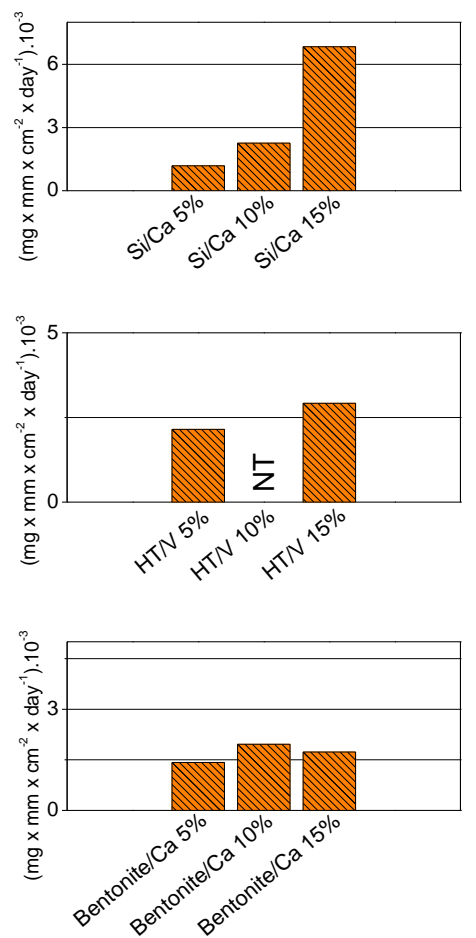

$\mathrm{Cl}^{-}$
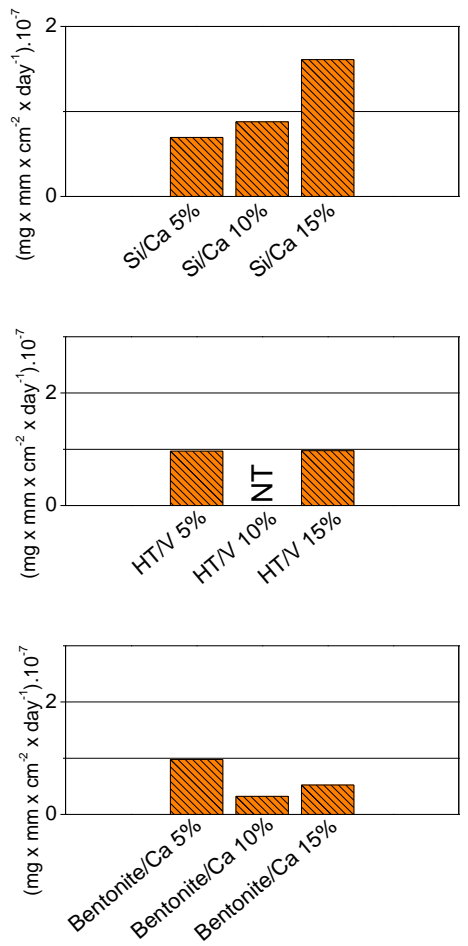

Figure 2 

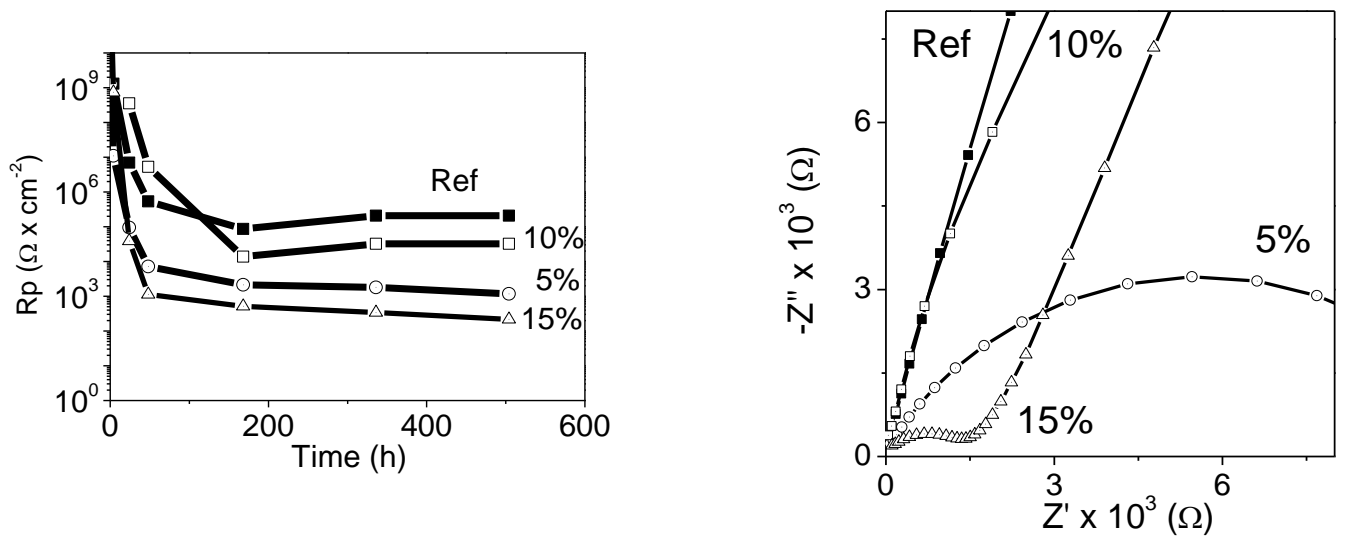

Figure 3 

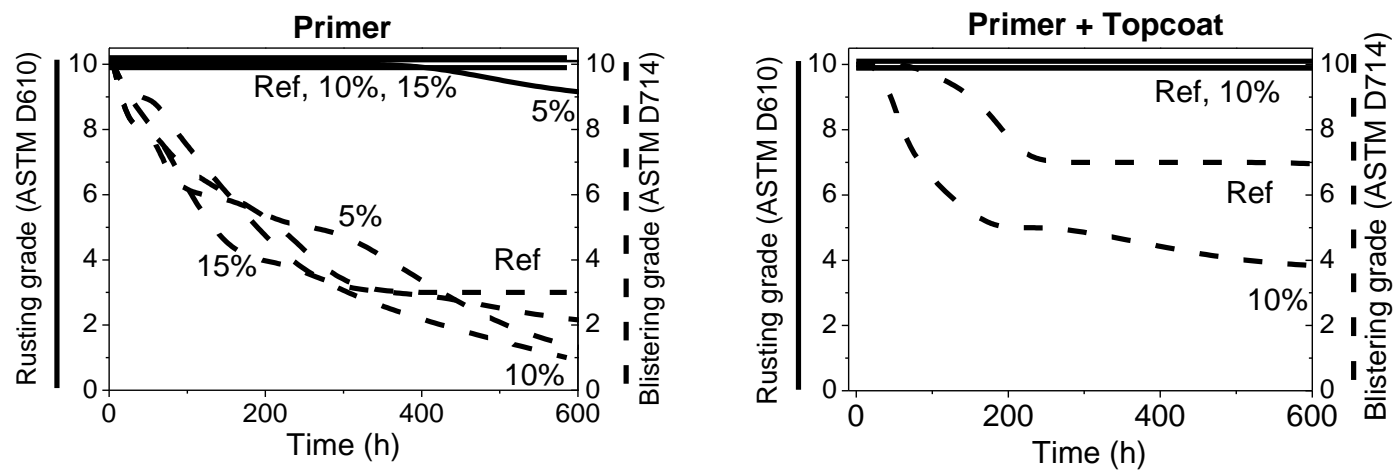

Figure 4 

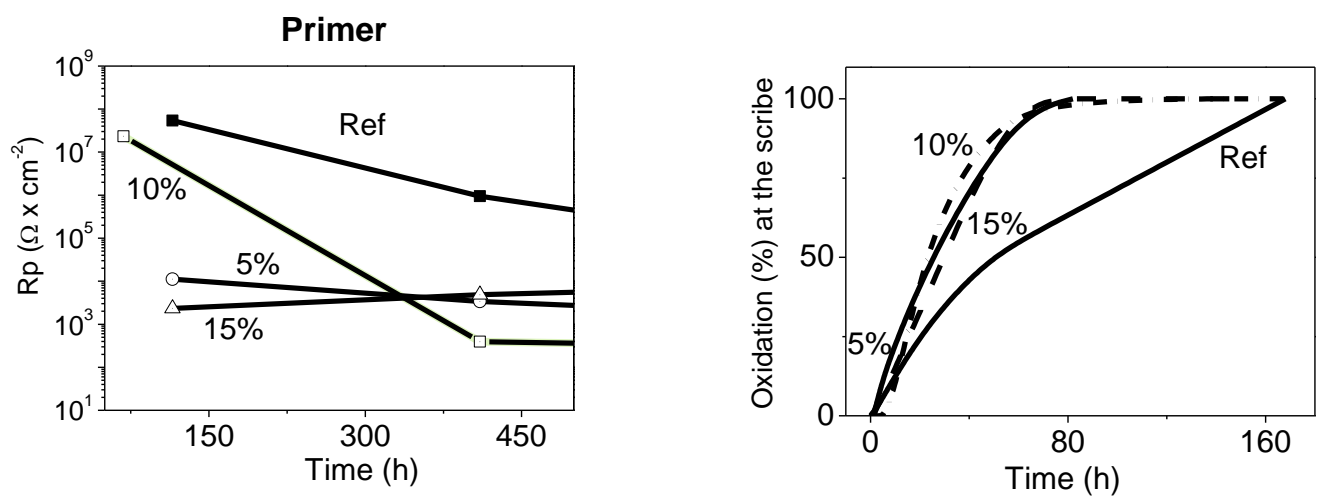

Figure 5 

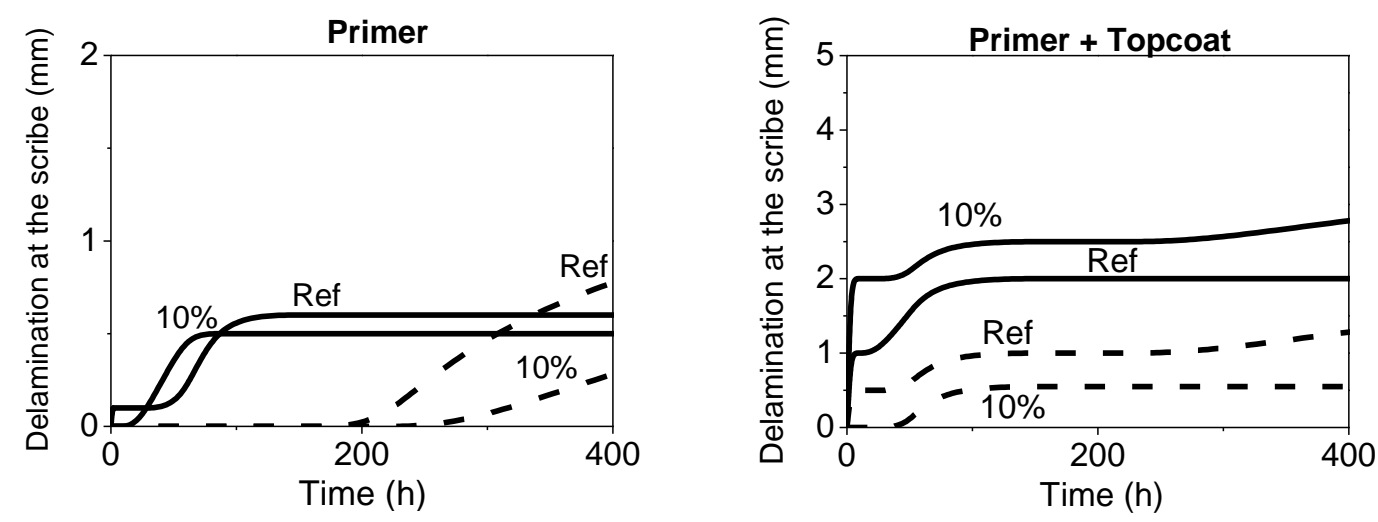

Figure 6 

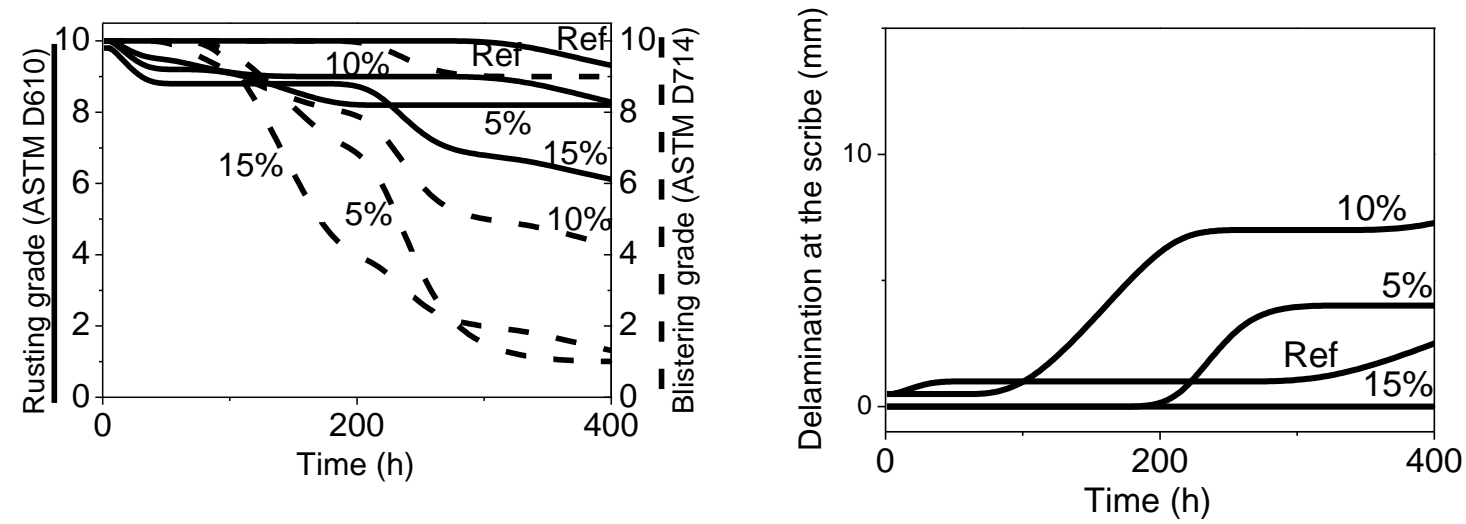

Figure 7 

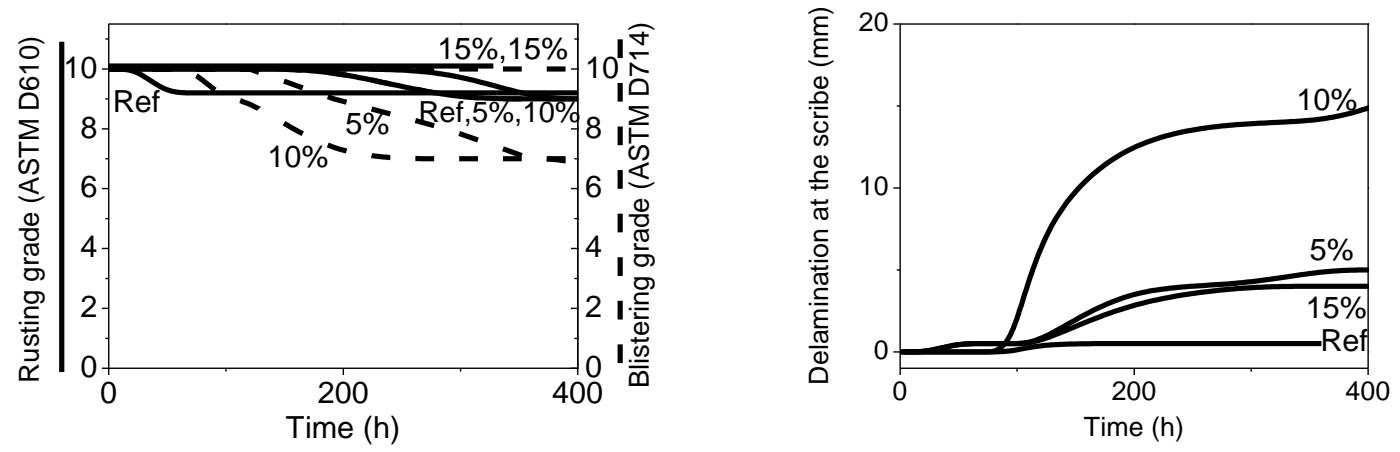

Figure 8 

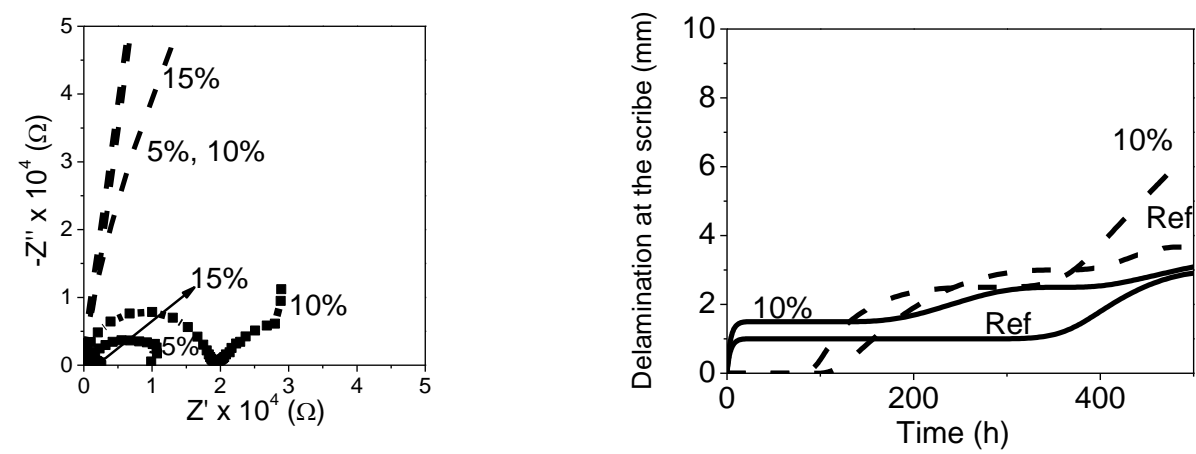

Figure 9 


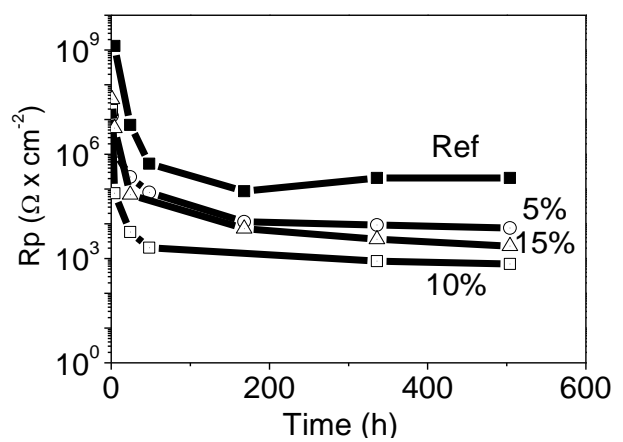

Figure 10 

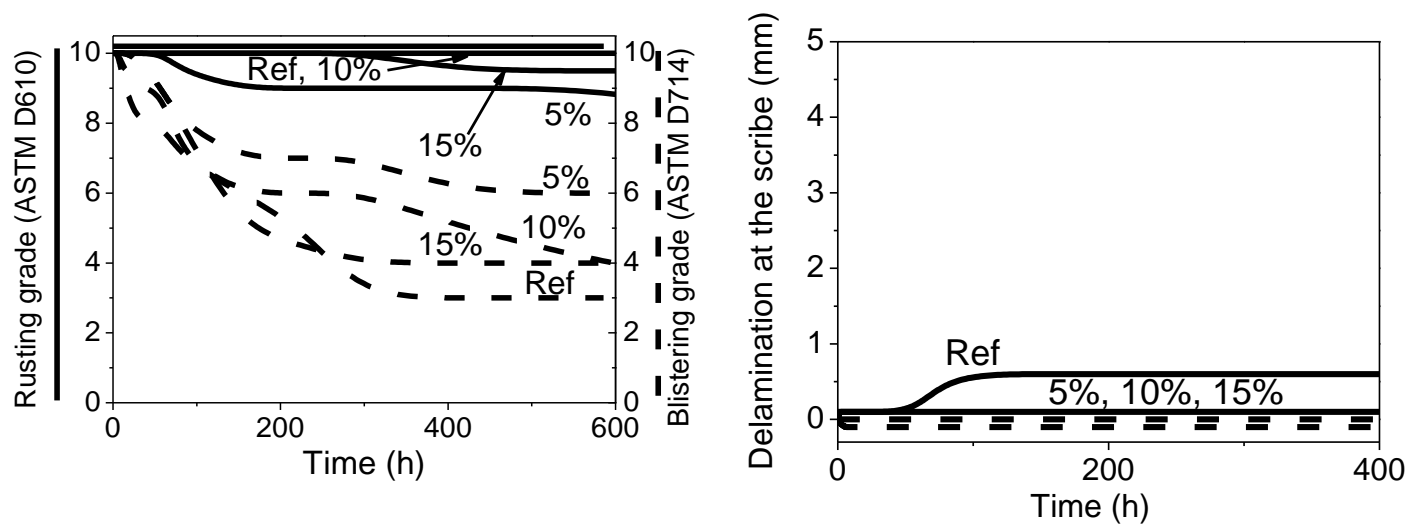

Figure 11 


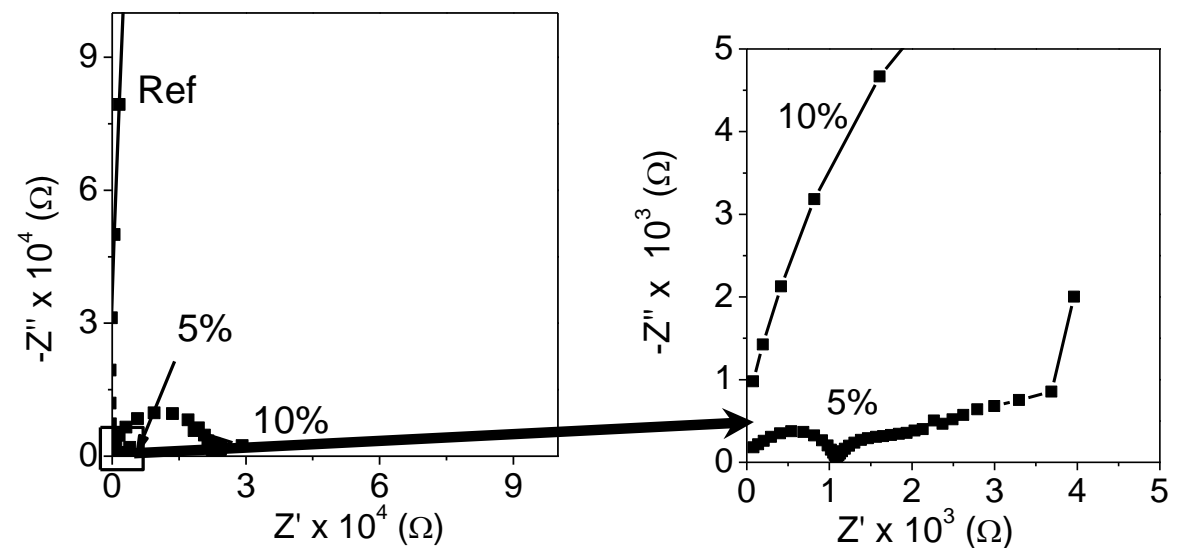

Figure 12 


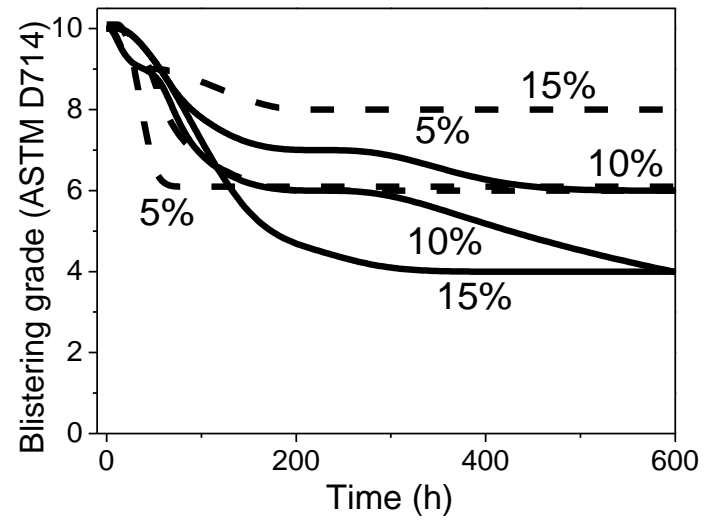

Figure 13 

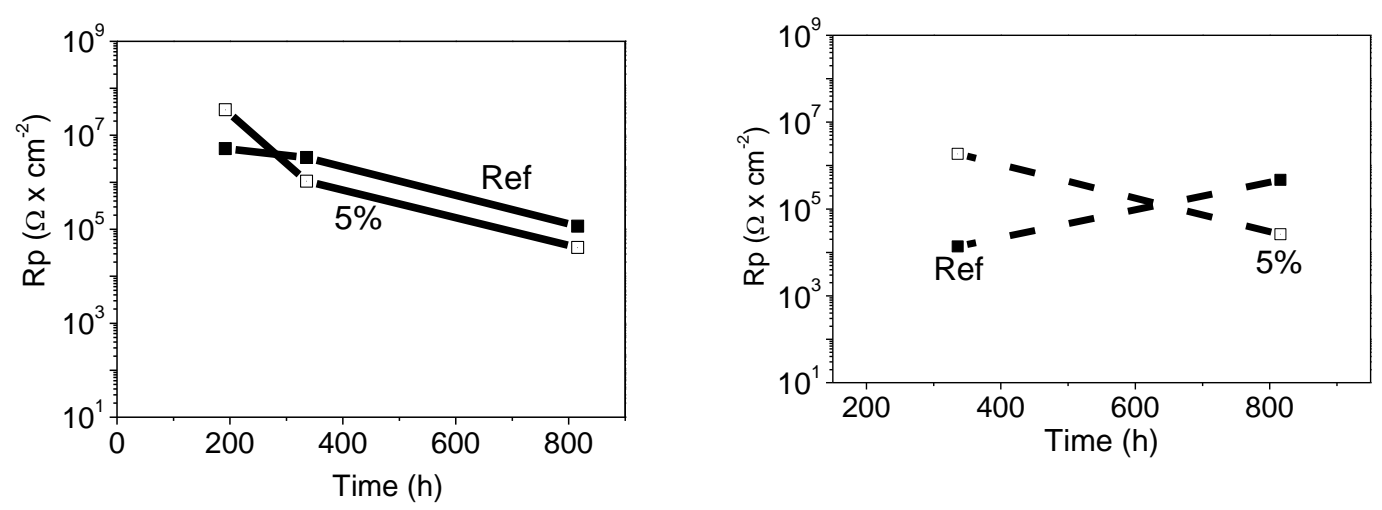

Figure 14 

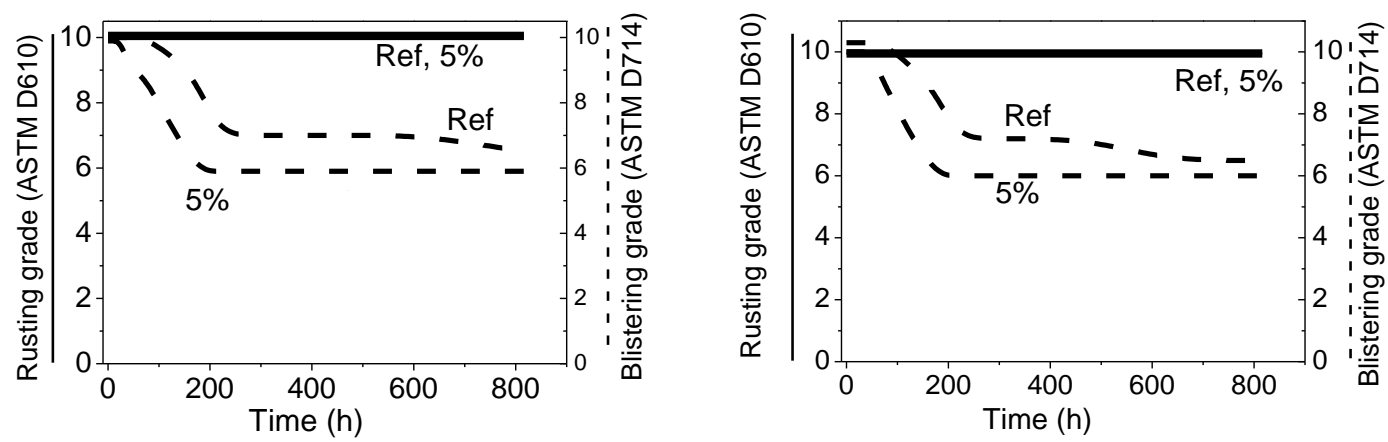

Figure 15 


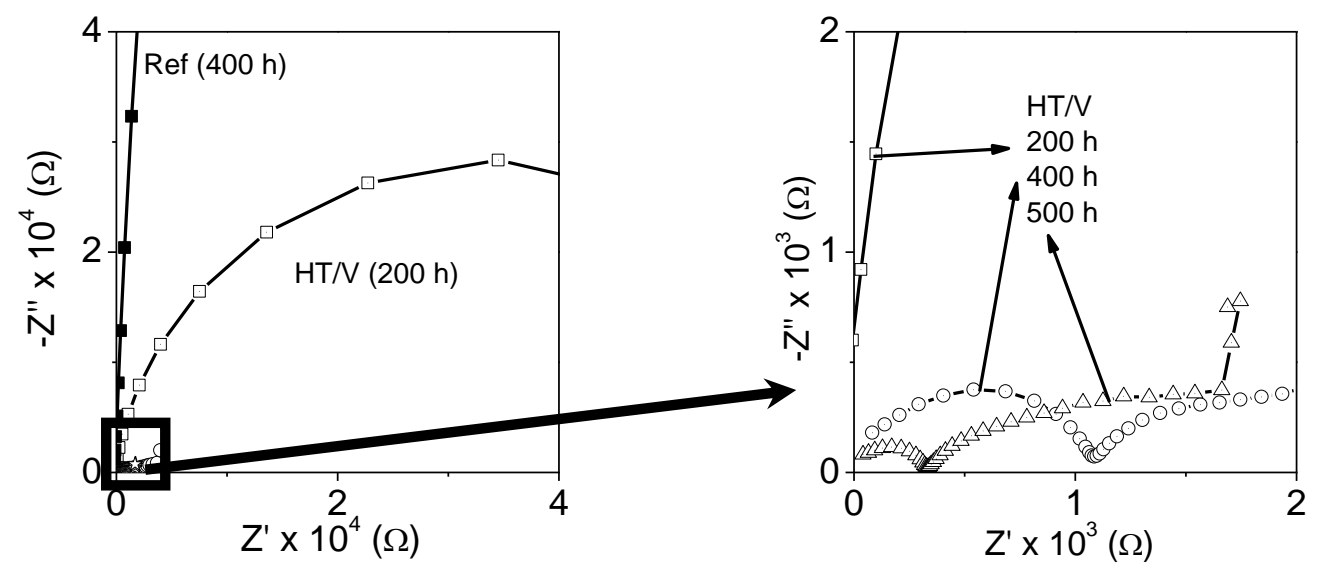

Figure 16 


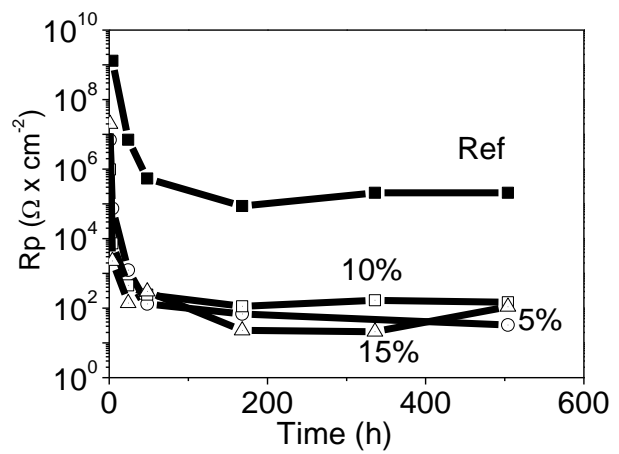

Figure 17 

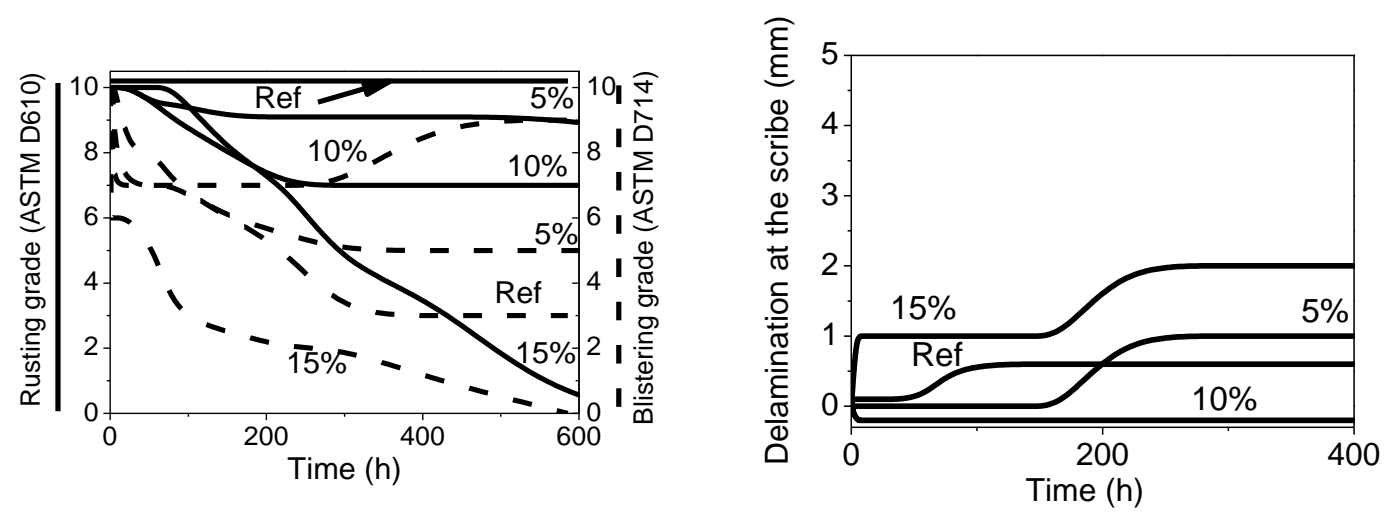

Figure 18 


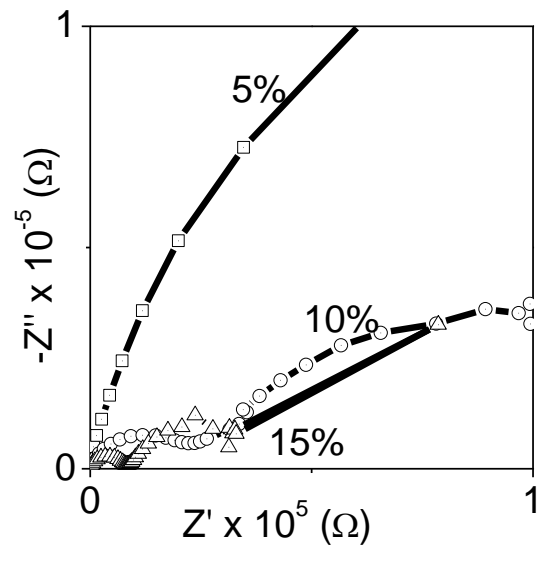

Figure 19 


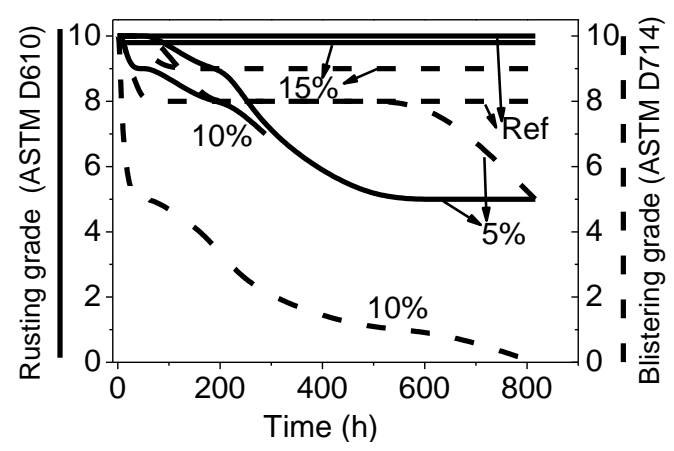

Figure 20 


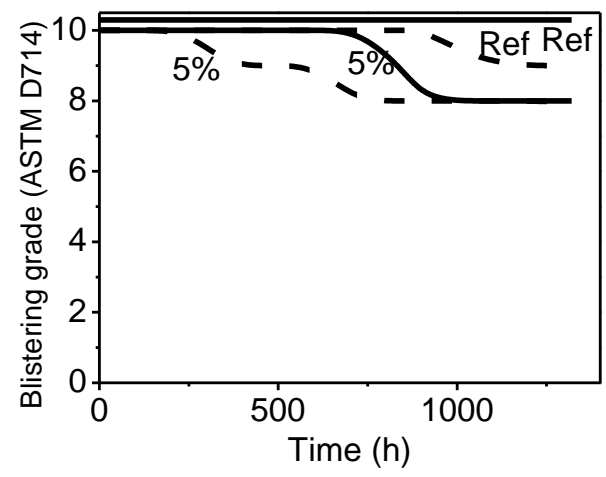

Figure 21 